\title{
El Movimiento Animalista en Costa Rica y la lucha por la ley para penalizar el maltrato animal: oportunidades y representaciones simbólicas
}

\author{
Diego Vega Rojas \\ Politólogo graduado por la Universidad de Costa Rica \\ https://orcid.org/0000-0002-0297-631X
}

Recepción: Julio 2020

Aceptación: Enero 2021

Cita recomendada. VEGA ROJAS, D., El Movimiento Animalista en Costa Rica y la lucha por la ley para penalizar el maltrato animal: oportunidades y representaciones simbólicas, dA. Derecho Animal (Forum of Animal Law Studies) 12/1 (2021). - DOI https://doi.org/10.5565/rev/da.511

Agradecimientos. El autor desea agradecer a Celestina Brenes Porras, a Gerardo Hernández Naranjo y a sus lectores anónimos por las sugerencias dadas en distintos momentos del desarrollo de esta investigación

\section{Resumen}

Entre 2015 y 2017 Costa Rica vivió un ciclo de movilizaciones en favor de causas animalistas, la mayoría tenía por intención presionar para aprobar una ley que penalizara el maltrato hacia los animales con énfasis en las mascotas. En este texto se busca generar un análisis del Movimiento Animalista en Costa Rica centrado en la coyuntura de la lucha por la ley para penalizar el maltrato animal, dado que no existen investigaciones previas al respecto. El artículo se divide en siete acápites: la introducción, una recopilación histórica, tres secciones dedicadas a las teorías abordadas -teoría de nuevos movimientos sociales, estudios de fronteras simbólicas y teorías de performatividad-, luego se presenta el análisis y se finaliza con las conclusiones. Se parte de un estudio de caso con base en la revisión documental de libros y artículos académicos, que se ha complementado con entrevistas semiabiertas a activistas que han ocupado posiciones de liderazgo. Fueron identificadas las principales oportunidades que le permitieron a los liderazgos bienestaristas llevar la lucha por la ley contra el maltrato animal hasta su aprobación efectiva. Se identificaron sus motivaciones y las representaciones simbólicas que hicieron de estas, al tiempo que se hizo un esbozo inicial de los mismos elementos por parte de los sectores abolicionistas. La constitución del Movimiento Animalista giró en torno a la lucha por la obtención de la ley para penalizar el maltrato hacia los animales, lo cual refleja una predilección por la vía institucional. Los grupos abolicionistas son los que pueden reactivar el Movimiento luego de la aprobación de la ley, y las organizaciones bienestaristas han de ofrecerles su guía sin actitudes paternalistas, a la vez que deberán presionar al Estado para hacer cumplir la Ley $\mathrm{N}^{\circ} 9458$ en medio de un ambiente político marcado por la austeridad fiscal.

Palabras clave: Movimiento Animalista; Animalismo; Costa Rica; Sociedad Civil; Legislación animalista; Nuevos movimientos sociales; Fronteras simbólicas; Performatividad; Acciones colectivas; Representaciones simbólicas.

Abstract - The Animal Movement in Costa Rica and the Struggle for the Law to Penalize Animal Abuse: Opportunities and Symbolic Representations

Between 2015 and 2017, Costa Rica witnessed a period of mobilizations in favour of animal causes, most of which were directed towards passing a law to penalize animal abuse, with an emphasis on pets. This research seeks to produce an analysis of the Costa Rican Animal Movement focused on the circumstances of the 
struggle for the law against animal abuse, given that it has never before been investigated. The article is divided into seven parts: the introduction, a historical summary, three sections for the theories being addressed - the new social movements theory, the studies on symbolic boundaries, and theories on performativity -, the analysis, and finally, the conclusions. It is based on a case study involving a documentary review of academic books and articles, which has been supplemented with semi-structured interviews with activists that have held leadership positions. It identifies the main opportunities that allowed welfarist leaderships to bring the struggle for the law against animal abuse to effective approval. It identifies their motives and the symbolic representations made of them at the time when an initial outline of these elements was made about the abolitionist sectors. The formation of the Animal Movement revolves around the struggle for obtaining the law to penalize animal abuse, reflecting a preference for institutional means. Abolitionist groups are those that can revive the movement following the passing of the law, and welfarist organisations must offer guidance in a non-paternalistic way, while at the same time pressure the state to enforce Law $\mathrm{N}^{\circ} 9458$ amid a political environment troubled by fiscal austerity.

Keywords: Animal Movement; Animalism; Costa Rica; Civil Society; Animal Legislation; New social movements; Symbolic boundaries; Performativity; Collective actions; Symbolic representations.

\section{Indice}

1. Introducción

2. Historia del Movimiento Animalista en Costa Rica

3. Teoría de nuevos movimientos sociales

4. Estudios de fronteras simbólicas

5. Teorías sobre performatividad

6. Análisis del Movimiento Animalista en Costa Rica

7. Conclusiones

8. Referencias bibliográficas

\section{Introducción ${ }^{1}$}

Entre 2015 y 2017 Costa Rica vivió un ciclo de movilizaciones en favor de causas animalistas, la mayoría tenía por intención presionar para aprobar una ley en la Asamblea Legislativa que penalizara el maltrato hacia los animales con énfasis en las mascotas, aunque también se pueden encontrar dentro de este periodo otras acciones con una tónica más marcadamente antiespecista.

Como bien han indicado Vázquez \& Valencia ${ }^{2}$, la filosofía antiespecista ha permeado el debate público en sectores tan diversos como la Sociedad Civil, los parlamentos, los medios de comunicación, y también dentro de la academia, donde un nuevo giro animalista está buscando generar un cambio de paradigma en favor de la construcción de una hegemonía no especista, lo cual incluye también un mayor interés por el estudio de los derechos de los animales y sus implicaciones desde las ciencias sociales.

A pesar de lo anterior, resulta sorprendente notar que en Costa Rica escasean las investigaciones académicas enfocadas en los estudios animalistas, y la mayor parte se centran en el ámbito legal. Todavía no existen investigaciones centradas en el análisis del Movimiento Animalista costarricense y en las acciones colectivas realizadas en pro de la defensa de los animales, tampoco se ha escrito sobre la coyuntura mencionada.

\footnotetext{
${ }^{1}$ El investigador desea explicitar que se considera vegetariano y que, aunque nunca ha sido miembro activo de una organización animalista, sí ha sido voluntario en proyectos específicos. También participó, desde el ámbito partidario, en la negociación de la Ley $\mathrm{N}^{\circ} 9458$ cuyo propósito principal era penalizar el maltrato contra los animales. Al momento de finalizar este texto había permanecido inactivo en el activismo animalista, sin embargo, es importante tomar en cuenta su pasión en el tema y cómo este podría permear el análisis sobre el tema en cuestión.

${ }^{2}$ VÁZQUEZ, R., VALENCIA, A. La creciente importancia de los debates antiespecistas en la teoría política contemporánea: del bienestarismo al abolicionismo, en Revista Española de Ciencia Política (2016) 148 y149. 
Así, la primera investigación aparece en 1990, donde Monique Zeller Van Engelen ${ }^{3}$ analiza las relaciones entre humanos y animales en distintos ámbitos, haciendo un recorrido por la historia universal pero dando espacio además a la legislación como a la cultura costarricense, y a la legislación del momento en otros países. La autora concluye que es necesario darles estatus legal a los animales desde una perspectiva que les otorgue protección por derecho propio y no en función de los seres humanos. Asimismo conceptualiza la crueldad como una distorsión del comportamiento humano, para lo cual llama a reforzar el aspecto educativo con una perspectiva orientada hacia la coexistencia pacífica entre los humanos y los otros animales.

Luego, Cabibbo Guillén ${ }^{4}$ realiza un estudio de las garantías jurídicas que existían por parte del Estado costarricense para resguardar a los animales domésticos hasta el año 2014. La autora encuentra una deficiencia en la protección animal desde el Estado, lo cual atribuye al desinterés por parte de las autoridades que se refleja en la falta de instrumentos jurídicos efectivos, en la inexistencia de competencias claras sobre los organismos estatales que deben velar en la materia, y en la carencia de educación sobre bienestar animal para la población general.

En una línea similar, Madrigal Rodríguez ${ }^{5}$ analiza la legislación costarricense vinculada con actividades donde participan animales, y al mismo tiempo realiza un estudio jurídico y axiológico de las diferencias entre los conceptos de Bienestar Animal y Derecho Animal. Se repite el hallazgo de que la legislación es insuficiente, aun desde un punto de vista bienestarista. Resalta la falta de protección a los animales de producción en el proceso de producción primaria. Se le suma la línea antropocéntrica de la Sala Constitucional, que ha indicado en sus resoluciones que la protección animal se define en función del ser humano. Finalmente, reconoce que aunque la perspectiva del Derecho de los animales todavía no es relevante desde el punto de vista doctrinario, es una tendencia que va en crecimiento y se nutre de corrientes externas al derecho.

El mismo año, Morales Picado ${ }^{6}$ emite su investigación donde analiza los fundamentos axiológicos del Derecho de los animales y las instituciones jurídicas relevantes en la materia dentro del sistema costarricense. Evidencia que el Derecho de los animales posee valores y bienes susceptibles de regulación jurídica. Asimismo, la legislación y la jurisprudencia costarricense reflejarían fundamentaciones axiológicas en defensa de los animales, pero tales elementos se encontrarían desordenadas y estaría faltando una justificación propia para la protección de los animales. Por lo tanto recomienda reorientar los valores costarricenses de modo que consideren a los animales merecedores de consideración moral y jurídica. Lo anterior se habría de acompañar de legislación que reconozca a los animales como seres sintientes y poseedores de intereses legítimos ante el Estado y las personas.

El estudio de la experimentación con animales en Costa Rica es otra área que ha sido explorada en algunos artículos, en los cuales se ha buscado abarcar la historia de este proceso en el país, los avances legales y los vacíos pendientes, y además la más reciente ofrece una guía para hacer este proceso más ético ${ }^{7}$. Todas ellas tienen en común la importancia que dan a realizar la experimentación con animales de forma humanitaria, aunque también en todas se parte de una postura a favor de la experimentación y carecen de una problematización de la falta de consentimiento por parte de los animales en estos procedimientos.

En la disciplina de la historia, resalta la investigación de Urbina Gaitán ${ }^{8}$ donde analiza el control ejercido por el Estado costarricense, entre 1870 y 1914, de las diversiones públicas relacionadas con animales. Explica que se buscó proscribir las peleas de gallos y regular las corridas de toros con la intención de moderar el comportamiento de los sectores populares en la capital costarricense. Además reconoce que, si bien dicha legislación tenía alcances nacionales, en la práctica no se puede confirmar que el Estado haya logrado mantener un control efectivo fuera del Valle Central.

En la antropología se puede sacar a colación una serie de artículos enmarcados en la investigación "iSe muere gallo bueno! Jóvenes, galleras y gallos de pelea" de la Escuela de Antropología de la Universidad de

\footnotetext{
${ }^{3}$ ZELLER VAN ENGELEN, M. La protección jurídica del animal en Costa Rica (Tesis para optar por el grado de Licenciatura en Derecho) (San José 1990) 137, 145, 148 y 149.

${ }^{4}$ CABIBBO GUILLÉN, M. Garantías jurídicas para la protección de los animales domésticos (Tesis para optar por el grado de Master Profesional en Derecho Ambiental) (San José 2014) Xiii,121\&122.

${ }^{5}$ MADRIGAL RODRÍGUEZ, P. Legislación de bienestar animal en Costa Rica: Un análisis jurídico formal sobre la protección legal animal y el proceso del proyecto de ley de penalización del maltrato animal (Tesis para optar por el grado de Licenciatura en Derecho) (San José 2015) vii,viii,148 y 149.

${ }^{6}$ MORALES PICADO, A. Derecho de los animales en el sistema jurídico costarricense: un análisis desde una perspectiva axiológicojurídica (Tesis para optar por el grado de Licenciatura en Derecho) (San José 2015) 2, 120 y121.

${ }^{7}$ SUÁREZ ESQUIVEL, M., ESTRADA KÖNIG, S. Bienestar animal en investigación biomédica, en Rev. Ciencias Veterinarias 29 (2011) 21 y 33; GRANADOS-ZÚÑIGA, J. Uso de animales de experimentación en la investigación biomédica en Costa Rica, en Acta méd. costarric. 52 (2010) 134 y 135; GRANADOS-ZÚÑIGA, J., PAZOS SANOU, L. Legislación para el uso de animales de laboratorio en Costa Rica, en Med. leg. Costa Rica 15 (1998) 2, 4 y 6.

${ }^{8}$ URBINA GAITÁN, C. Homogeneizando culturas. Peleas de gallos, corridas de toros y Estado en Costa Rica (1870-1914), en Revista de Ciencias Sociales (Cr) 3 (2000) 59 y 66.
} 
Costa Rica: el primero consiste en un análisis crítico de discurso que estudia imágenes construidas por la prensa costarricense que buscarían naturalizar la violencia perpetuada por las personas que participan en peleas de gallos para abstraerla de la violencia general de la sociedad ${ }^{9}$. El segundo expone el testimonio de un gallero para intentar aportar al conocimiento de la crianza y pelea de gallos desde su propia perspectiva y así evidenciar la complejidad del escenario social de interés ${ }^{10}$. El último se trata de una colección de observaciones etnográficas que buscan explicar el fenómeno de la socialidad gallera, y se concluye que esta dinámica funciona como contraposición estética pero reproduce la misma violencia de la cultura dominante en Costa Rica ${ }^{11}$. En todas ellas está ausente la problematización del maltrato animal.

Por último, la obra más reciente se circunscribe al campo de la filosofía, en la cual Camacho Chacón, Castro Murillo y Reyes Moreno ${ }^{12}$ hacen un recorrido por el desarrollo histórico del concepto científico de bienestar animal y pretenden interpretarlo de forma crítica, hasta llegar a la conclusión de que las consideraciones ofrecidas por la ciencia del bienestar animal ofrecen avances con respecto de prácticas anteriores que no tenían ningún cuidado por la integridad de los animales, pero han de ser comprendidas como herramientas provisionales mientras se desarrollan propuestas bioéticas y morales más respetuosas y sustentables.

Después de dar este recorrido por los estudios realizados en Costa Rica, queda en claro que el presente texto busca ser un punto de partida para comenzar a saldar esta deuda académica, de modo que se busca generar un análisis del Movimiento Animalista haciendo énfasis en la coyuntura de la lucha por la ley para penalizar el maltrato animal, y buscando identificar las oportunidades y representaciones simbólicas que encontraron los principales liderazgos para lograr su aprobación en la Asamblea Legislativa.

\subsection{Metodología}

La investigación se circunscribe dentro del estudio de caso, el cual es entendido como un subconjunto de métodos que aspiran a generalizaciones acumulativas y progresivas sobre la vida social, y busca desarrollar $\mathrm{y}$ aplicar estándares claros para juzgar si algunas generalizaciones explican el mundo social mejor que otras ${ }^{13}$. Además se parte de la lógica abductiva, entendida como la búsqueda de "teorías o marcos de referencia para proponer posibles explicaciones a datos observados en contextos específicos" ${ }^{14}$. Es decir, se ha seleccionado aquellas teorías que explican mejor este caso en concreto a la vez que se identifican sus puntos contrastantes.

De esta manera, el texto se encuentra divida en dos partes fundamentales: una recopilación de la historia del Movimiento Animalista costarricense, y un análisis ecléctico del Movimiento a partir de tres corrientes teóricas principales, a saber, la teoría de nuevos movimientos sociales, los estudios de fronteras simbólicas y las teorías de performatividad.

Para realizar la recopilación histórica se ha optado por la revisión documental de libros y artículos académicos como fuente primaria de obtención de la información, pero siendo que esta es escasa, se ha complementado con entrevistas semiabiertas a activistas que han ocupado posiciones de liderazgo dentro del Movimiento en distintos momentos: Juan Carlos Peralta, actual Presidente de la Asociación para el Bienestar y el Amparo de los Animales, Olga Rodríguez, actual presidenta de la Promotora Bienestar Animal, Gisela Vico Pesch, actual Presidenta de la Asociación Nacional Protectora de Animales, Yadira Pintor Moreno, fundadora de Marcha contra el Maltrato Animal en Costa Rica, y Hilda Durán, ex presidenta de la Asociación para la Protección Animal de Costa Rica y ex miembro de la Sociedad Protectora de Animales.

Ya que todas estas asociaciones pueden identificarse como bienestaristas ${ }^{15}$, se buscó también obtener la visión abolicionista ${ }^{16}$ dentro del Movimiento, para lo cual se contactó con el Frente de Resistencia Animal

\footnotetext{
${ }^{9}$ RODRÍGUEZ AGUILAR, O., ALPÍZAR LOBO, N. Las peleas de gallos en la prensa escrita costarricense: un Análisis Crítico del Discurso en algunas noticias del diario La Nación S.A., en Rev. Rupturas 4 (2014) 52, 66 y 67.

${ }^{10}$ RODRÍGUEZ AGUILAR, O. Gallos de pelea: algunas precisiones desde el diálogo con un gallero, en Cuadernos de Antropología 24 (2014) 63 y 64.

${ }^{11}$ RODRÍGUEZ AGUILAR, O. “iSe muere gallo bueno!”. Peleas, socialidad y violencia galleras en Costa Rica, en Anuario de Estudios Centroamericanos (2015) 304, 322, 323 y 324.

${ }^{12}$ CAMACHO CHACÓN, J. CASTRO MURILLO, M., REYES MORENO, L. La ciencia del bienestar animal: conceptualización y discusión, en Rev. Filosofía Univ. Costa Rica 58 (2019) 90 y 97.

${ }^{13}$ GEORGE, A., BENETT, A. Case studies and Theory Development in the Social Sciences (Massachusetts 2005$) 24$.

${ }^{14}$ PARRA, J. El arte del muestreo cualitativo y su importancia para la evaluación y la investigación de políticas públicas: una aproximación realista, en OPERA 25 (2019) 126.

${ }^{15} \mathrm{Al}$ hablar de bienestarismo se refiere a la corriente que intenta mejorar las condiciones de vida de los animales sin cuestionar el supuesto de que son propiedad humana, y por tanto, no buscan erradicar su explotación. Ver VÁZQUEZ, R., VALENCIA, A. La creciente importancia de los debates antiespecistas en la teoría política contemporánea: del bienestarismo al abolicionismo, en Revista Española de Ciencia Política (2016) 153.

${ }^{16}$ La corriente abolicionista aboga por abolir las relaciones de propiedad entre humanos y animales, y plantea la búsqueda de una comunidad mixta entre humanos y no humanos que participen en un proyecto comunitario, pero personal e intransferible. Ver 66 Derecho Animal. Forum of Animal Law Studies, vol. 12/1
} 
y de la Tierra, primera organización identificada con el Movimiento de Liberación Animal en el país y que designó dos voceros para contactarse en el marco de esta investigación, cuyos apellidos no aparecerán por solicitud expresa de estos: Boris y Edgar.

Asimismo, se acude a la revisión documental de medios periodísticos costarricenses como fuente auxiliar, específicamente, se recurre al diario La Nación. A la hora de desarrollar el análisis del Movimiento desde las teorías, se han tomado en cuenta las respuestas de los activistas en las entrevistas y se han complementado con las fuentes recién mencionadas.

Por otro lado, la principal limitación a la hora de desarrollar la investigación tuvo que ver con la información escasa acerca de las acciones colectivas durante el siglo XX. En futuras investigaciones es necesario precisar los detalles de este periodo, y en especial se ha de indagar más sobre el aparente periodo de silencio comprendido entre los 50s y los 80 s. Profundizar en la interacción mantenida entre los partidos políticos y el Movimiento Animalista, así como los procesos de diálogo interseccional con otros movimientos sociales, son aspectos que podrían resultar de interés en futuros análisis.

Finalmente, existe una corriente incipiente de literatura que se enfoca en el aspecto emocional del activismo y los movimientos sociales. En la presente investigación se analizó escasamente el aspecto emocional, el cual se limitó al papel que juega en los objetos de los rituales performativos. Esta línea teórica se ha empleado para analizar las estrategias y motivaciones de activistas animalistas en otras latitudes arrojando resultados interesantes, y vale la pena buscar replicar dichos estudios pues podrían generar conocimiento de utilidad en la materia.

Así bien, este texto se divide en seis acápites además de la presente sección: el primero se trata de la recopilación histórica, los tres siguientes corresponden a la síntesis de las teorías abordadas, luego se presenta el análisis y se finaliza con una sección dedicada a las conclusiones.

\section{Historia del Movimiento Animalista en Costa Rica}

\section{1. Antecedentes}

\section{1. 1. Primera mitad del siglo XX}

La primera Organización No Gubernamental $(\mathrm{ONG})$ de carácter animalista formalizada en Costa Rica fue la Sociedad Protectora de Animales (SPA), actualmente Asociación Nacional Protectora de Animales (ANPA). Fue fundada el domingo 7 de junio de 1914 y su dirigencia se encontraba compuesta originalmente por políticos, banqueros y profesionales. La primera junta directiva de la SPA fue la siguiente: Walter J. Field en la presidencia, Cleto González Víquez ${ }^{17}$ en la vicepresidencia, John F. Stahl en la secretaría, y José C. Zeledón, Ricardo Güell G., Manuel Dengo, Rafael Cañas y el Lic. Fabio Baudrit en las vocalías ${ }^{18}$.

Vico Pesch ${ }^{19}$, presidenta de ANPA, agrega que la SPA era una sociedad honoraria, enfocada en animales de tracción como mulas y caballos, cuyo papel era más simbólico que encaminado a las acciones concretas. Esto se ejemplifica en el hecho de que el primer acuerdo de esta ONG en 1914 fue un voto de agradecimiento al entonces presidente Ricardo Jiménez Oreamuno por haber vetado, el 25 de junio de 1912, el decreto que permitía las peleas de gallos, a pesar de su reconocida afición a esta actividad ${ }^{20}$.

Al respecto, también cabe agregar un extracto del discurso que diera el ex presidente Jiménez Oreamuno ante la Asamblea Legislativa buscando el apoyo de los diputados a su veto:

Bien veo que hay hombres que reclaman, como su derecho, el armar de navajas á los gallos para que se maten; pero al mismo tiempo vemos niñas que se congregan para abrir á las avecillas cautivas las puertas de sus jaulas ${ }^{21}$.

Si bien no hay mayor registro escrito en la materia, pareciera ser que el ex presidente está describiendo la existencia de expresiones que podrían considerarse acciones primordiales de Liberación Animal ya a mediados de los 10 s del siglo pasado. En futuras investigaciones sería importante buscar indagar a mayor profundidad sobre estas acciones.

\footnotetext{
VÁZQUEZ, R., VALENCIA, A. La creciente importancia de los debates antiespecistas en la teoría política contemporánea: del bienestarismo al abolicionismo, en Revista Española de Ciencia Política (2016) 161.

${ }^{17}$ Cabe agregar que Cleto González Víquez fue presidente de la República de Costa Rica en dos ocasiones, primero de 1906 a 1910 , y luego de 1928 a 1932.

${ }^{18}$ URBINA GAITÁN, C. Homogeneizando culturas. Peleas de gallos, corridas de toros y Estado en Costa Rica (1870-1914), en Revista de Ciencias Sociales (Cr) 3 (2000) 64.

${ }^{19}$ VICO PESCH, G. Comunicación personal (21 de agosto de 2018).

${ }^{20}$ URBINA GAITÁN, C. Homogeneizando culturas. Peleas de gallos, corridas de toros y Estado en Costa Rica (1870-1914), en Revista de Ciencias Sociales (Cr) 3 (2000) 64.

${ }^{21}$ FERNÁNDEZ RIVERA, F. Juegos de gallos. Un veto histórico y un discurso parlamentario olvidado (San José 1984$) 13$.
} 
En su segundo mandato, Ricardo Jiménez Oreamuno también genera otra acción significativa en la materia: la emisión del Decreto sobre Maltrato de Animales (Decreto $\mathrm{N}^{\circ} 10$ del 22 de agosto de 1924). Dicho texto corresponde, según Madrigal Rodríguez ${ }^{22}$, a la primera norma enfocada en la protección de animales en Costa Rica, no ya en sentido exclusivamente instrumental sino pensando también en el bienestar de estos.

Ahora bien, aunque no se ha logrado precisar la fecha exacta, en algún punto de la primera mitad del siglo XX la doctora María Isabel Calderón ${ }^{23}$ toma las riendas de la SPA, quien estudiara medicina en los Estados Unidos de América y trajera de la nación del norte sus ideas sobre la protección de los animales. Ella se dedica sobre todo a atender el maltrato de animales de producción en las zonas rurales del país, donde organiza grupos de campesinos sensibilizados en la lucha para fungir como una suerte de inspectores ${ }^{24}$.

El nivel de organización es tal que ya en los 40s, con Rafael Ángel Calderón Guardia en el poder, logra obtener una subvención estatal para los labores de activismo. A partir de ese punto, a los campesinos organizados por la doctora se les otorga un carné que los faculta con carácter oficial a hacer inspecciones a los animales y, en caso de encontrarse indicios de maltrato animal, también tienen la autoridad suficiente para solicitar a las autoridades judiciales locales que tomen acciones en los casos en concreto ${ }^{25}$.

Parece ser que tras la muerte de la doctora Calderón en los 40s, las acciones en defensa de los animales pasan por un periodo de pasividad que no volverán a reanudarse hasta los $80 \mathrm{~s}$, cuando la SPA se reactiva ${ }^{26}$.

No obstante, antes de seguir se ha de agregar que los primeros proteccionistas también se pueden rastrear desde el siglo XX, centrados en la defensa de la vida silvestre y caracterizados por permanecer en el anonimato debido a los calificativos negativos que recibían, pues se les asociaba con la vagabundería, el comunismo, a los hombres con la homosexualidad y a las mujeres con persona solteras, "solteronas". Estos proteccionistas seguirán con este tipo de acciones ocultas hasta a mediados del siglo $\mathrm{XX}^{27}$.

Es importante indicar que muchos de ellos tuvieron sus orígenes como pajareros, es decir, personas que se dedicaban a atrapar pájaros en las montañas y luego los mantenían en cautiverio para explotar sus cantos. Algunos se fueron sensibilizando a través del mismo acto de explotación animal. Parece ser que en sus orígenes también recibieron influencia formativa por parte del Ministerio de Agricultura, institución con la cual mantenían cercanía. Una vez convertidos en activistas, estos proteccionistas también coordinaban acciones con la $\mathrm{SPA}^{28}$.

\section{1. 2. Segunda mitad del siglo $X X$}

La SPA se reactiva el 11 de enero de 1980 para enfocarse en la lucha contra las corridas de toros, momento en que se reinventa como ANPA $^{29}$. En esta fase la ONG se enfocaba en atender denuncias de maltrato animal a lo largo y ancho del país, en un estilo similar al activismo en los 40s, con la diferencia de que en esta etapa se le dará un carácter central a lucha contra el maltrato en eventos de entretenimiento con animales $^{30}$.

Así, ANPA se hace presente en eventos que son tradicionales en la época, como carreras de cintas, el cerdo encebado, las peleas de gallos y las corridas de toros. En los tres primeros casos se dedican a asistir a las actividades para denunciar in situ la realización de estas, que ya eran sancionadas por sus actividades inhumanas. En el caso de las peleas de gallos, que habían sido ilegalizadas desde los 10s, debían además recurrir a espías que se infiltraran en la realización de los eventos pues sus organizadores tenían medidas para cancelar las actividades cuando alertaban la presencia inminente de los activistas ${ }^{31}$.

Otro caso es el de las corridas de toros, que como eran legales y tenían mayor aprobación moral entre la sociedad, tenían que cambiar de tácticas. Al atender tales eventos buscaban negociar con los organizadores

\footnotetext{
${ }^{22}$ MADRIGAL RODRÍGUEZ, L. Legislación de bienestar animal en Costa Rica: Un análisis jurídico-formal sobre la protección legal animal y el proceso del proyecto de ley penalización del maltrato animal (Tesis para optar por el grado de Licenciatura en Derecho) (San José 2015) 76.

${ }^{23}$ Barahona Riera ubica dentro de los miembros de la Liga Feminista en Costa Rica a una doctora de nombre Isabel Calderón. Ver BARAHONA RIERA, M. Las sufragistas de Costa Rica (San José 1994) 76. Aunque al momento de finalización del presente texto no se pudo comprobar que se tratara de la misma persona, tomando en cuenta la coincidencia temporal, resulta importante ahondar en esta posibilidad en futuras investigaciones. De comprobarse, podría dar origen a investigaciones sobre interseccionalidad entre feminismo y animalismo en Costa Rica.

${ }^{24}$ DURÁN, H. Comunicación personal (17 de febrero de 2020); DURÁN, H. Comunicación personal (31 de enero de 2020).

${ }^{25}$ DURÁN, H. Comunicación personal (31 de enero de 2020).

${ }^{26}$ DURÁN, H. Comunicación personal (31 de enero de 2020).

${ }^{27}$ RODRÍGUEZ, O. Comunicación personal (17 de noviembre de 2017).

${ }^{28}$ DURÁN, H. Comunicación personal (17 de febrero de 2020).

${ }^{29}$ Asociación Nacional Protectora de Animales. Página Web: https://www.facebook.com/pg/ANPACR/about/?ref=page_internal; Vico Pesch, Comunicación personal (21 de agosto de 2018).

${ }^{30}$ DURÁN, H. Comunicación personal (31 de enero de 2020).

${ }^{31}$ DURÁN, H. Comunicación personal (31 de enero de 2020).

68 Derecho Animal. Forum of Animal Law Studies, vol. 12/1
} 
para que evitaran prácticas que consideraban de crueldad excesiva, como era el uso de las banderillas ${ }^{32}$.

Por otro lado, Olga Rodríguez ingresa a la sección de asesores del Ministerio de Educación Pública (MEP) en 1986, bióloga quien ya trabajaba como profesora para el Ministerio. Aunque le niegan la sugerencia de prohibir la práctica de las vivisecciones, Olga Rodríguez y una colega deciden elaborar los nuevos planes de estudio omitiendo la parte de las vivisecciones sin avisar a sus superiores. En aquel momento esta práctica deja de ser promovida por parte del MEP ${ }^{33}$.

En los siguientes años, hasta ya entrada la década de los 90s, Rodríguez y su compañera se dedicarán a convencer asesores del MEP de quitar contenidos que naturalizan el maltrato animal, ya sea en poemas, en música, entre otros. También elaborarán nuevos planes de estudio que incluyen la protección de perros y gatos junto a Gerardo Huertas, biólogo y director del World Society for the Protection of Animals ${ }^{34}$ (WSPA) en Costa Rica en aquel entonces. Se dedicarán en los siguientes años a sensibilizar a los profesores en distintos puntos del país ${ }^{35}$.

Ahora bien, tras un proceso de renovación generacional, ANPA pasa en los 90s por una fase en la que se constituye como albergue, pero el esfuerzo se vuelve inviable debido a que la cantidad de animales que reciben supera la capacidad para satisfacer sus necesidades. Entonces ANPA busca transformarse en un centro de adopciones para intentar reducir el exceso de animales, pero este esfuerzo tampoco genera resultados positivos. De esta manera, entre los años 1999 y 2000, tras un debate interno, finaliza la etapa de adopciones y sus miembros deciden centrarse en la elaboración de material educativo para niños, así como en la organización de talleres formativos en escuelas de educación primaria ${ }^{36}$.

Cabe agregar que en 1999, a partir del debate suscitado, algunos miembros salen de la ONG y fundan la Asociación para el Bienestar y el Amparo Animal (ABAA), la cual se enfocó en rescatar animales para luego darlos en adopción, bajo el concepto de casa-cuna. Con el tiempo, dicha organización se fue especializando, de modo que pasa a dedicarse a los servicios médicos veterinarios de bajo costo en las comunidades y también a la asesoría legislativa en materia de bienestar animal ${ }^{37}$.

\section{2. Articulación del Movimiento}

Yadira Pintor, inquieta por el hecho de que la ley vigente contra el maltrato animal en aquel entonces no ofrece ningún tipo de pena ${ }^{38}$, solo contravenciones, decide organizar la primera caminata contra el maltrato animal en 2009, donde participa un grupo pequeño de personas ${ }^{39}$. Desde los 80 s, esta fue la primera acción colectiva documentada en el marco de la lucha contra el maltrato hacia los animales, de donde surgió el grupo Marcha contra el Maltrato Animal en Costa Rica, que siguió repitiendo la marcha durante nueve años hasta la última en 2017. Conforme creció la asistencia a la marcha, se buscó además que el trayecto de esta concluyera en una feria de bienestar animal ${ }^{40}$.

Es importante señalar que Pintor creó un formulario que repartió en esa primera marcha donde se invitaba a firmar para repudiar el maltrato animal, y las firmas recogidas fueron utilizadas para solicitar el proyecto de ley $\mathrm{N}^{\circ} 18698$ por iniciativa popular, que en 2017 se convertiría en Ley de la República ${ }^{41}$.

En 2011, con la marcha contra el maltrato animal en auge, Pintor entró en contacto con ABAA y a partir de esta reunión se articuló un grupo de fuerzas de aproximadamente 120 organizaciones, grupos de profesionales (biólogos, abogados), rescatistas y ciudadanos interesados, para afinar el documento que fue presentado a la Asamblea Legislativa. De ese colectivo, surge un grupo de redactores entre los que se pueden contar a Sugey Poveda, Licdo. Collado, Débora Portilla, Chiro Rojas y los cinco firmantes del documento: Fabián Moya, Patricia Abadía, Yadira Pintor, Olga Rodríguez y la Dra. Ileana Céspedes del Servicio Nacional de Salud Animal (SENASA) ${ }^{42}$.

Ahora bien, en 2011 también es fundado el Frente de Resistencia Animal y de la Tierra (FRAT), un grupo con tintes anarquistas que viene a darle al Movimiento un ala más anti sistémica. Es formado a partir

\footnotetext{
32 DURÁN, H. Comunicación personal (31 de enero de 2020).

${ }^{33}$ RODRÍGUEZ, O. Comunicación personal (17 de noviembre de 2017).

${ }^{34}$ Actualmente se denomina World Animal Protection (WPA).

${ }^{35}$ RODRÍGUEZ, O. Comunicación personal (17 de noviembre de 2017).

${ }^{36}$ VICO PESCH, G. Comunicación personal (21 de agosto de 2018).

${ }^{37}$ PERALTA, J. Comunicación personal (15 de noviembre de 2017).

${ }^{38}$ Ley N 7451 , emitida en 1998.

${ }^{39}$ PINTOR MORENO, Y. Comunicación personal (14 de julio de 2020).

${ }^{40}$ PINTOR MORENO, Y. Comunicación personal (14 de julio de 2020); PERALTA, J. Comunicación personal (15 de noviembre de 2017).

${ }^{41}$ PINTOR MORENO, Y. Comunicación personal (14 de julio de 2020); PERALTA, J. Comunicación personal (15 de noviembre de 2017).

42 PINTOR MORENO, Y. Comunicación personal (14 de julio de 2020); PERALTA, J. Comunicación personal (15 de noviembre de 2017).
} 
de miembros de otros colectivos veganos y vegetarianos, por ejemplo, VivaVeg y La revolución de la cuchara, pero siendo que estos se enfocaban en cambiar el estilo de vida de las personas, existía una inquietud por formar una organización que tuviera una presencia más fuerte, con acciones enmarcadas en el Movimiento de Liberación Animal ${ }^{43}$.

El 26 de diciembre de 2011 se realiza la primera concentración anti corridas desde los 80s, llevada a cabo en Zapote y organizada por el FRAT, que tenía como objetivo denunciar la crueldad y el abuso de los animales en las corridas de toros a la tica ${ }^{4}$. Esta actividad se ha seguido realizando todos los años hasta la actualidad, y se han diversificado las organizaciones participantes.

El 20 de diciembre de 2012 entra a regir la Ley $\mathrm{N}^{\circ} 9106^{45}$, Reforma Ley de Conservación de la Vida Silvestre, un triunfo del Movimiento producto de una lucha paralela por obtener una norma que diera mayor protección a la vida silvestre. Tiene el hito de ser la primera ley aprobada a través del instrumento de democracia directa denominado Iniciativa Popular, y es importante destacar que fue impulsada por los sectores animalistas más vinculados a los Movimientos Ambientalistas y Ecologistas, en concreto, este esfuerzo fue liderado por la Asociación Preservacionista de Flora y Fauna silvestre (Apreflofas).

El 25 de mayo de 2013 es concretada en la Plaza de la Cultura la primera concentración contra la experimentación en animales, en la cual el FRAT se centró en denunciar a la empresa Procter \& Gamble, por ser la empresa más grande a nivel mundial que acoge este tipo de prácticas ${ }^{46}$.

La primera Marcha por la Liberación Animal, desde el Parque Central al Zoológico Simón Bolívar, data del domingo 28 de julio de 2013, y fue convocada también por el FRAT, destinada a condenar el encierro de animales con fines lucrativos, principalmente en zoológicos ${ }^{47}$.

La marcha recién mencionada presenta dos particularidades interesantes. En primer lugar, las dos primeras muestras de teatro guerrilla con temática animalista se registran en dicha actividad: una demostración del trato que reciben los animales en un matadero, y otra demostración que trató de ejemplificar la crueldad de la industria cosmética y la experimentación animal. El segundo dato relevante es que en ella ocurre el primer acto represivo por parte de las fuerzas policiales en una acción colectiva animalista, dejando como resultado a tres activistas detenidos ${ }^{48}$.

Volviendo a las acciones institucionales, en 2016, con el proceso de negociación del proyecto de ley en la Asamblea Legislativa ya en proceso, el Movimiento necesitaba crear presión política, por lo tanto se decide emitir un nuevo proyecto de ley que se enviaría a referéndum en abril. Este proceso fue liderado por un movimiento social en ciernes, compuesto por ciudadanos, organizaciones, rescatistas, grupos sociales que se aglutinan en torno al discurso de la aparente pasividad del primer poder de la República por avanzar en este proceso $^{49}$.

El jueves 14 de abril de 2016 se organiza una marcha contra el maltrato animal que resulta relevante porque se da un nuevo caso de represión policial. En esta ocasión, unos activistas quemaron dos muñecos que representaban a los ex diputados Ottón Solís y Otto Guevara, quienes manifestaron comentarios negativos sobre el proyecto de ley. Durante dicha situación aparece un escuadrón antimotines y se lleva presos a algunos

\footnotetext{
${ }^{43}$ BORIS \& EDGAR. Comunicación personal (23 de agosto de 2018).

${ }^{44}$ Frente de Resistencia Animal y de la Tierra. Página Web: https://frat.noblogs.org/post/2011/12/26/manifiesto-anti-corridas-dezapote 2011-antitaurino/

${ }^{45}$ La ley suscitada consiste en una serie de reformas y adiciones a la Ley de conservación de vida silvestre que data de 1992. Penaliza la caza deportiva y únicamente se permite la caza para el control de especies y para la subsistencia de los pueblos originarios, debidamente regulada. También se reglamente la colecta, la tenencia y extracción de animales silvestres, para lo cual se ordena la creación de listas oficiales de especies en peligro de extinción. Crea el Registro Nacional de Vida Silvestre, encargado de controlar los sitios de manejo de vida silvestre públicos y privados. Además prohíbe la exhibición temporal o permanente de vida silvestre nativa o exótica en espectáculos circenses. Un aspecto llamativo es que permite la comercialización de vida silvestre cuando esta no está dentro de las listas de poblaciones reducidas. Ver Asamblea Legislativa de la República de Costa Rica. N9106 REFORMAS Y ADICIONES A LA LEY DE CONSERVACIÓN DE VIDA SILVESTRE, LEY N. ${ }^{\circ}$ 7317, DE 30 DE OCTUBRE DE 1992, en La Gaceta 75 (24 de abril de 2013) 1-24.

${ }^{46}$ Frente de Resistencia Animal y de la Tierra. Página Web: https://frat.noblogs.org/post/2014/05/17/concentracion-informativa-antiproctergamble-2014/

${ }^{47}$ Frente de Resistencia Animal y de la Tierra. Página Web: https://frat.noblogs.org/post/2013/08/02/posicion-ante-los-zoologicos/

${ }^{48}$ Frente de Resistencia Animal y de la Tierra. Página Web: https://frat.noblogs.org/post/2013/08/02/comunicado-en-referencia-a-lamarcha-por-la-liberacion-animal/

49 Peralta, J. Comunicación personal (15 de noviembre de 2017). Cabe agregar que la ley consiste en una serie de adiciones a la Ley №4573, Código Penal, y a la Ley ํ7451, Bienestar de los Animales. Entre sus novedades, resalta el aumento de multas por peleas de animales, hibridación de animales para aumentar su peligrosidad, violación de disposiciones sobre experimentación, entre otras. Asimismo se sanciona con prisión la crueldad, el maltrato y la muerte dolosa de animales domésticos y domesticados, así como las peleas entre estos. La pena privativa puede ser sustituida por una pena alternativa por disposición del Juez, y las organizaciones inscritas ante el Registro Judicial pueden representar los intereses difusos de los animales. Ver Asamblea Legislativa de la República de Costa Rica. N$^{\circ} 9458$ REFORMAS DE LA LEY N. ${ }^{\circ} 4573$, CÓDIGO PENAL, DE 4 DE MAYO DE 1970 Y REFORMAS DE LA LEY N. ${ }^{\circ} 7451$, BIENESTAR DE LOS ANIMALES, DE 16 DE NOVIEMBRE DE 1994, en La Gaceta 152 (26 de junio de 2017) 18.
} 
de los activistas que realizaron el "performance", hecho tras el cual se retira la mayor parte de las personas que acuden a la marcha ${ }^{50}$.

El proceso de referéndum fue detenido por el Tribunal Supremo de Elecciones alegando que el proyecto de ley contenía cláusulas inconstitucionales, sin embargo la presión por parte de la Sociedad Civil a través de marchas y declaraciones públicas no mermó, hasta que el $1^{\circ}$ de junio de 2017 fue aprobado el proyecto de ley por Iniciativa Popular, convirtiéndose así en la Ley $\mathrm{N}^{\circ} 9458^{51}$.

El 11 de junio de 2017 el presidente de la República convocó a una marcha para celebrar la aprobación de la ley, y luego firmó públicamente dicho documento, dejándolo así en vigor ${ }^{52}$. Esta es la última manifestación masiva que ha ocurrido en torno a las luchas animalistas.

Aún está por verse si el Movimiento podrá consolidarse más allá de esta coyuntura, pero hasta la fecha de elaboración del presente texto seguía en estado de pasividad, y son solo algunas organizaciones abolicionistas las que continúan generando acciones colectivas esporádicas. Destaca, por ejemplo, Animal Save Costa Rica, que en el marco de la pandemia del Covid-19 se ha dedicado a hacer vigilias virtuales ${ }^{53}$ y también ha realizado algunas concentraciones en áreas públicas de San José para hacer consciencia sobre la relación entre el consumo de carne animal y la aparición de la pandemia ${ }^{54}$. La misma organización se dedica además a hacer vigilias afuera de algunos mataderos del país como forma de demostración pública de empatía ${ }^{55}$.

Otra organización incipiente es Furia Antiespecista, que se ha sumado a las concentraciones ya institucionalizadas afuera del redondel de Zapote ${ }^{56}$. De igual manera dicha organización ha llamado a sumarse a la Marcha del $8 \mathrm{M}$ con un mensaje de interseccionalidad entre luchas feministas, anticapitalistas y antiespecistas ${ }^{57}$.

Finalmente, el FRAT se ha centrado en organizar el Mercadito Vegano ${ }^{58}$, pero también ha realizado boicots en los topes nacionales ${ }^{59}$. Asimismo han convocado a marchas feministas ${ }^{60}$ y a acciones colectivas contra la represión policial en respuesta a manifestaciones contra las políticas de austeridad ${ }^{61}$, entre otras acciones interseccionales. Es importante recalcar que todos estos grupos abolicionistas tienen una presencia marcada y continua en redes sociales.

En cuanto a la Ley $\mathrm{N}^{\circ} 9458$, es importante señalar que hasta la fecha de redacción de este artículo parecía haber generado resultados limitados. En primer lugar, solo dos casos de aparente maltrato se han llevado a juicio hasta el final, ambos absolutorios. Por otra parte, a las instituciones encargadas de atender las denuncias relacionadas con maltrato y crueldad animal, SENASA y el Organismo de Investigación Judicial, se les añadieron nuevas funciones sin que la ley garantizara la dotación de recursos suficientes ${ }^{62}$. En una coyuntura marcada por el paradigma de la austeridad fiscal, esto se ha traducido en que tales entes carecen de los recursos necesarios para atender sus deberes legales efectivamente.

Habiendo finalizado el recuento histórico, es tiempo de pasar ahora a la exposición de las teorías que serán empleadas para generar el análisis.

\section{Teoría de nuevos movimientos sociales}

\footnotetext{
${ }^{50}$ MATA BLANCO, E. Zafarrancho entre "ambientalistas" por quema de imágenes de Ottón Solís y Otto Guevara, en La Nación (14 de abril de 2016). Página Web: https://www.nacion.com/el-pais/politica/zafarrancho-entre-ambientalistas-por-quema-de-imagenesde-otton-solis-y-otto-guevara/HXYBBDCFC5C3HBVX5UUVM6ZIAU/story/

${ }^{51}$ PERALTA, J. Comunicación personal (15 de noviembre de 2017).

52 CALvo, N. Presidente firma Ley de Bienestar Animal, en La Nación (11 de junio de 2017). Página Web: http://www.nacion.com/ciencia/medio-ambiente/presidente-firma-ley-de-bienestaranimal/ASRB62SOUZEBTHKX7NUE5TGHQQ/story/

${ }^{53}$ Animal Save Costa Rica. Página Web:

https://www.facebook.com/events/306040743774113/?acontext=\%7B\%22source\%22\%3A5\%2C\%22action_history\%22\%3A[\%7B $\% 22$ surface $\% 22 \% 3 \mathrm{~A} \% 22$ page $\% 22 \% 2 \mathrm{C} \% 22$ mechanism $\% 22 \% 3 \mathrm{~A} \% 22$ main_list $\% 22 \% 2 \mathrm{C} \% 22$ extra data $\% 22 \% 3 \mathrm{~A} \% 22 \% 5 \mathrm{C} \% 22[] \%$ $5 \mathrm{C} \% 22 \% 22 \% 7 \mathrm{D}] \% 2 \mathrm{C} \% 22$ has_source $\% 22 \% 3$ Atrue $\% 7 \mathrm{D}$

${ }^{54}$ Animal Save Costa Rica. Página Web: https://www.instagram.com/p/CE5WjViJGFv/?igshid=iw9bs4o5kz6t

${ }^{55}$ Animal Save Costa Rica. Página Web: https://www.instagram.com/p/CEEkUCRJd13/?igshid=hnbe7f703zcj

${ }^{56}$ Furia Antiespecista. Página Web: https://www.instagram.com/p/B6tql6yHTAi/?igshid=5iisyogahi0w

${ }^{57}$ Furia Antiespecista. Página Web: https://www.instagram.com/p/B9AAQ2on3zm/?igshid=1crhi9bka2gh0

${ }^{58}$ Frente de Resistencia Animal y de la Tierra. Página Web: https://www.instagram.com/p/B7rqiVTlttU/?igshid=tztrkdlupvr; Boris \& Edgar. Comunicación personal (23 de agosto de 2018).

${ }^{59}$ Frente de Resistencia Animal y de la Tierra. Página Web: https://www.instagram.com/p/CJT3QupBBdP/?igshid=5ha1g95n0ql3

${ }^{60}$ Frente de Resistencia Animal y de la Tierra. Página Web: https://www.instagram.com/p/CH8RV0ZnXyx/?igshid=vcgptn9i0yj1

${ }^{61}$ Frente de Resistencia Animal y de la Tierra. Página Web: https://www.instagram.com/p/CIIinEVH4o1/?igshid=1qobihy0f7xi3

${ }^{62}$ Cerdas, D. Ley contra maltrato animal se convirtió en un fiasco, en La Nación (26 de enero de 2020). Página Web: https://www.nacion.com/el-pais/gobierno/ley-contra-maltrato-animal-se-convirtio-en-

un/RMNWMNH7ZFD7VGQKIMD7J3SIGU/story/
} 
La teoría de nuevos movimientos sociales parte del concepto de mundo de la vida de Habermas para explicar que el proceso productivo capitalista ha impuesto la lógica productiva fuera de la esfera económica hacia otras esferas que eran consideradas parte del ámbito privado. Así, los nuevos movimientos serían la respuesta defensiva a estas transformaciones, donde la clase media jugaría un papel preponderante debido a la modificación que está sufriendo en su estilo de vida. Los movimientos sociales tradicionales se diferencian de los nuevos porque los primeros reivindican valores materiales e individualistas, frente a la búsqueda de autorrealización y construcción de significados de los segundos ${ }^{63}$.

En este marco, Tarrow ${ }^{64}$ describe a los movimientos sociales como un conjunto de acciones colectivas planteados por personas que carecen de acceso regular a las instituciones estatales y que comparten objetivos comunes y solidaridad en una interacción mantenida frente a las élites, los oponentes y las autoridades. Además, el autor ${ }^{65}$ sostiene que los descontentos encuentran oportunidades favorables de acción durante la aplicación de reformas al sistema, cuando se abre el acceso institucional, cuando cambian las alianzas políticas o cuando emergen conflictos entre las élites.

Por su parte, Melucci ${ }^{66}$ encuentra que la forma de organización de los movimientos contemporáneos se convierte en un objetivo en sí misma, ya que adquiere carácter de mensaje y de desafío simbólico a los patrones dominantes, por tanto se convierte en la base de la identidad interna y del enfrentamiento con el sistema al mismo tiempo. Los movimientos redefinen el significado de la acción social para la sociedad, pues practican el cambio por el cual están luchando. El movimiento en sí como un nuevo medio es el mensaje.

No obstante, estas características también los hacen vulnerable a dos riesgos distintos ${ }^{67}$ :

1. Posibilidad permanente de fragmentación en sectas marginales o de integración al mercado con fines instrumentales.

2. La dificultad de conciliar estas nuevas demandas con las estructuras viejas de los partidos políticos.

\section{Estudios de fronteras simbólicas}

Elizabeth Cherry ${ }^{68}$ se sitúa desde los estudios étnicos que investigan el rol de las fronteras simbólicas en la consolidación de diferencias entre grupos, y adapta el cuerpo conceptual a los procesos culturales que dan forma a los movimientos sociales.

De acuerdo con $\mathrm{Alba}^{69}$ las fronteras simbólicas pueden ser claras o difuminadas. En el primer caso carecen de ambigüedad, por lo tanto los individuos saben en todo momento de qué lado están. En el segundo surgen zonas de auto representación y representación social que permiten locaciones ambiguas con respecto de la frontera. La frontera animal-humano se trata de un caso claro de una frontera simbólica, y los activistas animalistas intentan difuminarla al denunciar el carácter arbitrario y socialmente construido de dicha frontera al convertirlo en el centro de atención, es decir, al hacer lo implícito explícito ${ }^{70}$.

Cherry ${ }^{71}$ ha podido identificar dos estrategias principales para promover la transformación de fronteras por parte de activistas animalistas:

1. Difuminación de fronteras gracias al empleo de estrategias universalistas.

2. Combinación de fronteras a nivel físico, discursivo e iconográfico.

Antes de continuar es importante aclarar que, por difuminación de fronteras, se entiende al proceso por el cual el perfil social involucrado en la frontera pasa de ser claro a ser turbio, o en otras palabras, la locación de los individuos respecto de la frontera aparece indeterminado ${ }^{72}$.

\footnotetext{
${ }^{63}$ RODRÍGUEZ GIRALT, I. El efecto de las TIC en la organización de la acción colectiva: la virtualización de los movimientos sociales, en UOC (2002) 7; ROSE, F. Toward a Class-Cultural Theory of Social Movements: Reinterpreting New Social Movements, en Sociological Forum 12 (1997) 464, 467 y 468.

${ }^{64}$ TARROW, S. El poder en movimiento. Los movimientos sociales, la acción colectiva y la política (Madrid 1997$) 17$ y 21.

${ }^{65}$ TARROW, S. El poder en movimiento. Los movimientos sociales, la acción colectiva y la política (Madrid 1997) 148.

${ }^{66}$ MELUCCI, A. Acción colectiva, vida cotidiana y democracia (Ciudad de México 1999) 74 y 75.

${ }^{67}$ MELUCCI, A. Acción colectiva, vida cotidiana y democracia (Ciudad de México 1999) 80.

${ }^{68}$ CHERRY, E. Shifting Symbolic Boundaries: Cultural Strategies of the Animal Rights Movement, en Sociological Forum 25 (2010) 452 y 454.

${ }^{69}$ ALBA, R. Bright vs. blurred boundaries: Second-generation assimilation and exclusion in France, Germany, and the United States, en Ethnic and Racial Studies 28 (2010) 22.

${ }^{70}$ CHERRY, E. Shifting Symbolic Boundaries: Cultural Strategies of the Animal Rights Movement, en Sociological Forum 25 (2010) 459 y 460.

${ }^{71}$ CHERRY, E. Shifting Symbolic Boundaries: Cultural Strategies of the Animal Rights Movement, en Sociological Forum 25 (2010) 455 y 458.

${ }^{72}$ ALBA, R. Bright vs. blurred boundaries: Second-generation assimilation and exclusion in France, Germany, and the United States,

72 Derecho Animal. Forum of Animal Law Studies, vol. 12/1
} 
Cuando se habla de estrategias universalistas se busca enfatizar un criterio que permite incluir a todas las personas más allá de características particulares como clase, credo o raza ${ }^{73}$. La idea es desdibujar la frontera al crear una suerte de comunidad de pertenencia global antes que local ${ }^{74}$.

Por otro lado, la combinación de fronteras describe el proceso de asimilación en el que un individuo se mueve de un grupo al otro, sin que haya un cambio real en la frontera en $\mathrm{si}^{75}$. En el caso de los estudios étnicos, se estudia el proceso por el cual los inmigrantes o una minoría étnica emprenden acciones que los hagan más similares a los "insiders". En cuanto a los movimientos sociales, el objetivo final de la combinación de fronteras es desplazar las fronteras simbólicas, a nivel colectivo antes que individual ${ }^{76}$.

Los activistas por los derechos de los animales utilizan dos principales estrategias universalistas de difuminación de fronteras ${ }^{77}$ :

1. La universalización de la victimización de humanos y animales posicionando los dos grupos como víctimas de violencia y opresión, así como evidenciando las condiciones estructurales similares que legitiman tales situaciones.

2. La universalización de la lucha animalista al posicionar la equivalencia entre el movimiento animalista y los movimientos por los derechos humanos, con lo cual se intenta legitimar el primero al posicionarlo en el mismo nivel de movimientos históricos exitosos.

Así también, se identifican dos formas principales de combinación de fronteras ${ }^{78}$ :

1. Desmantelamiento de la frontera animal-humano al utilizar cuerpos humanos como si fueran cuerpos animales, a través de representaciones iconográficas, específicamente enmarcadas en el teatro guerrilla.

2. Desmantelamiento de la frontera entre animales de compañía y animales de producción a nivel discursivo e iconográfico, al representar a los primeros en las actividades atroces que sufren los segundos a lo largo del proceso productivo.

\section{Teorías sobre performatividad}

Durkheim considera que los vínculos sociales poseen una naturaleza moral en dos niveles: la moral de la obligación que responde al deber, y la moral del bien que tiene que ver con el deseo. Una sociedad moral conjugaría ambos elementos acompañados de ideales compartidos que les den sentido colectivo. Asimismo, para mantener un equilibrio entre dichos elementos, hacen faltan las normas en su calidad de poderes simultáneamente exteriores y morales que pueden mantener el deseo bajo control ${ }^{79}$.

Así, el mismo autor define las normas como patrones de comportamiento que resultan cristalizados a partir de la necesidad de coordinar las acciones de las personas en situaciones recurrentes. En cambio, entiende los ideales como representaciones colectivas de cómo debería ser la vida, la naturaleza humana y la sociedad ${ }^{80}$.

Tomando en cuenta la distinción realizada por Durkheim entre normas e ideales, Jacobsson \& Lindblom ${ }^{81}$ conceptualizan a los activistas como seguidores de ideales. No obstante, al promover y practicar esos ideales, sus acciones suelen entrar en conflicto con las normas establecidas en la sociedad.

Si los activistas son definidos como transgresores de normas por el público general y las élites políticas, será más difícil que ganen apoyo significativo para su causa, mientras que si logran traducir sus ideas en

en Ethnic and Racial Studies 28 (2010) 23.

${ }^{73}$ LAMONT, M., BAIL, C. Bridging Boundaries: The Equalization Strategies of Stigmatized Ethno-racial Groups Compared, en Center for European Studies Working Paper Series (2008) 2.

${ }^{74}$ WIMMER, A. Elementary strategies of ethnic boundary making, en Ethnic and Racial Studies 31 (2008) 1042.

${ }^{75}$ ALBA, R. Bright vs. blurred boundaries: Second-generation assimilation and exclusion in France, Germany, and the United States, en Ethnic and Racial Studies 28 (2010) 23.

${ }^{76}$ CHERRY, E. Shifting Symbolic Boundaries: Cultural Strategies of the Animal Rights Movement, en Sociological Forum 25 (2010) 468.

${ }^{77}$ CHERRY, E. Shifting Symbolic Boundaries: Cultural Strategies of the Animal Rights Movement, en Sociological Forum 25 (2010) 461 y 466.

${ }^{78}$ CHERRY, E. Shifting Symbolic Boundaries: Cultural Strategies of the Animal Rights Movement, en Sociological Forum 25 (2010) 468 y 470.

${ }^{79}$ RODRÍGUEZ SEDANO, A., AGUILERA, J.C. De la constitución moral de la sociedad a la educación moral según Durkheim, en revista española de pedagogía (2009) 322, 324, 327 y 328.

${ }^{80}$ HALL, R. Communitarian Ethics and the Sociology of Morals: Alasdair Maclntyre and Emile Durkheim, en Sociological Focus 24 (1991) 97 y 98.

${ }^{81}$ JACOBSSON, K., LINDBLOM J. Moral Reflexivity and Dramaturgical Action in Social Movement Activism: The Case of the Plowshares and Animal Rights Sweden, en Social Movement Studies 11 (2011) 41 y 42. 
normas, existirá un mayor chance de que el cambio de comportamiento deseado en la sociedad se haga realidad. Entonces, para transmitir su mensaje con éxito y conseguir nuevos seguidores, los movimientos buscan estrategias para minimizar su rol como rebeldes y enfatizar su identidad como seguidores de ideales. Los autores adaptan los postulados de Goffman sobre performatividad para explicar cómo las puestas en escena de la acción colectiva responden a la forma de intentar resolver este conflicto ${ }^{82}$.

Así bien, Goffman ${ }^{83}$ define "performance" como toda actividad realizada por un individuo que ocurre durante un periodo de tiempo marcado por su presencia continua ante un conjunto particular de observadores, sobre quienes ejerce cierta influencia. Claro está, como esta investigación se centra en movimientos sociales no se entenderá el "performance" únicamente como un ejercicio de individuos, sino también de colectivos. Asimismo, se empleará el término de "performances" explícitos para designar al teatro guerrilla, y "performances" implícitos para identificar aquellos rituales más sutiles que suceden en las acciones colectivas.

Es importante indicar que el objetivo final de la performatividad en las sociedades seculares no es diferente de aquel de los rituales sagrados, es decir, ambos buscan crear conexiones emocionales con una audiencia a través de actores y textos, y así crear condiciones para proyectar significados culturales desde el "performance" a la audiencia ${ }^{84}$.

Aquí surge otro reto: ¿cómo generar significados influyentes a través del drama y al mismo tiempo negar performatividad? Básicamente, el "performance" debe mostrarse auténtico para tener éxito, los significantes en verdad parecen ser lo que buscan significar. Por este motivo los actores necesitan acceso a objetos materiales que posibiliten la realización de proyecciones simbólicas, o sea, objetos que sirvan de representaciones icónicas para ayudarlos a dramatizar y hacer vívida la moral que intentan representar ${ }^{85}$.

\section{Análisis del Movimiento Animalista en Costa Rica}

$\mathrm{Si}$, como dice Tarrow ${ }^{86}$, los movimientos sociales son desafíos colectivos planteados por personas que comparten objetivos comunes y solidaridad en una interacción mantenida con élites, oponentes y autoridades, entonces se puede considerar que se articula el Movimiento Animalista hasta 2009, cuando se organiza la primera marcha contra el maltrato animal. A partir de este proceso se multiplicaron las organizaciones animalistas de diversa índole y la mayor parte de ellas realizaron sus acciones colectivas en coordinación o con apoyo, total o parcial, de las personas que dieron origen a Marcha contra el Maltrato Animal en Costa Rica. Cabe resaltar que la alta presencia en las marchas pareciera girar en torno a la coyuntura del proyecto de ley contra el maltrato animal, antes de eso solo se observan acciones colectivas esporádicas, o acciones por medios completamente institucionales para avanzar en la defensa de los animales.

Ahora bien, es posible identificar que el punto más álgido de movilizaciones ocurrió entre 2015 con el proceso de referéndum y 2017 con la aprobación de la Ley №9458, pero ¿cómo se explica esto? Evidentemente dio resultado la estrategia detrás de los líderes del Movimiento para generar presión a través del referéndum en abril de 2016, con toda la cobertura mediática subsecuente. No obstante, ya las condiciones estaban presentes para que se diera este aumento en las movilizaciones.

Hay que recordar que en 2014 llega Luis Guillermo Solís Rivera al poder ejecutivo por el Partido Acción Ciudadana (PAC), siendo la primera vez que esta agrupación, reconocida por su orientación progresista, ganaba las elecciones. Asimismo, en la Asamblea Legislativa el PAC se convirtió en segunda fuerza política y el Frente Amplio (FA), partido de izquierda, fue la tercera fuerza, lo cual permitió una alianza orientada a causas progresistas ${ }^{87}$. En ese sentido, ambos promovían dentro de sus agendas la aprobación de la Ley suscitada ${ }^{88}$.

Como bien reconoce Pintor Moreno:

una de las cosas que nos ayudó bastante fue que Juan Carlos [Peralta] conocía al antiguo presidente, a Luis Guillermo [...] Nosotros nos reunimos antes de que a él lo eligieran presidente y él nos prometió

\footnotetext{
${ }^{82}$ JACOBSSON, K., LINDBLOM J. Moral Reflexivity and Dramaturgical Action in Social Movement Activism: The Case of the Plowshares and Animal Rights Sweden, en Social Movement Studies 11 (2011) 41 y 45.

${ }^{83}$ GOFFMAN, E. The Representation of Self in Everyday Life (Edinburgh 1956) 13.

${ }^{84}$ ALEXANDER, J. Cultural Pragmatics: Social Performance between Ritual and Strategy, en Sociological Theory 22 (2004) 547.

${ }^{85}$ ALEXANDER, J. Cultural Pragmatics: Social Performance between Ritual and Strategy, en Sociological Theory 22 (2004) 532 y 548.

${ }^{86}$ TARROW, S. El poder en movimiento. Los movimientos sociales, la acción colectiva y la política (Madrid 1997$) 17$ y 21.

${ }^{87}$ ROSALES-VALLADARES, R. Elecciones Costa Rica 2014: El aparente giro hacia el progresismo de izquierda mediante el triunfo del Partido Acción Ciudadana y el ascenso del Frente Amplio, en Anuario CIEP (2015) 163 y 170.

${ }^{88}$ Partido Acción Ciudadana. Página Web: https://pac.cr/pac-mantiene-su-compromiso-con-la-ley-de-bienestar-animal/; Partido Frente Amplio. Página Web: https://www.frenteamplio.org/frente-amplio-protege-bienestar-los-animales/

74 Derecho Animal. Forum of Animal Law Studies, vol. 12/1
} 
que iba a ayudarnos a aprobar la Ley ${ }^{89}$.

Diputados del Partido Unidad Social Cristiana (PUSC) y el Partido Liberación Nacional, los dos partidos históricos en Costa Rica, terminaron por apoyar la ley gracias a la presión popular y a las negociaciones ${ }^{90}$, tanto con líderes del Movimiento como con los diputados impulsores en el PAC y el FA. Esto quiere decir que el Movimiento encontró dos oportunidades que le permitió consolidar este ciclo de alta actividad: apertura institucional (Llegada del PAC al poder) y cambio de alianzas políticas (Alianza coyuntural PAC-FA en conjunto con diputados de otras fracciones).

Ahora bien, Pintor Moreno ${ }^{91}$ reconoce que "La marcha entonces lo que tenía era el objetivo de buscar el apoyo del Gobierno, de buscar sensibilizar a los costarricenses, y también de conseguir más firmas, esos eran los tres objetivos que tenía la marcha", demostrando así la orientación en torno a la aprobación de la Ley. Es cierto que habla de sensibilizar a los costarricenses, pero como se verá a continuación, se refiere principalmente a la sensibilización en torno al bienestar de animales mascota:

el "target" o el segmento al que yo quería llegar no eran las personas como yo que protestaban por el tema de bienestar animal, sino que era el tico promedio, que tiene a su mascota en la casa y que lo quiere y que lo aprecie, y que no quiere que se lo maltraten ${ }^{92}$.

A grandes rasgos no se aprecia la aseveración de Melucci ${ }^{93}$ sobre la forma de organización de los movimientos contemporáneos como un objetivo en sí misma, pues el Movimiento Animalista como un todo no propone un cambio sustancial en el estilo de vida, más allá de cumplir un mínimo moral que no debiera ser eludido dentro de las normas sociales hegemónicas como lo es el sancionar el maltrato y la crueldad hacia los animales mascota y animales silvestres. El Movimiento tenía como objetivo central la aprobación de la ley, y una vez alcanzado, se situó en un estado de pasividad.

Asimismo, todas las ONGs que centralizaron el proceso de negociación (ABAA, Marcha contra el Maltrato Animal en Costa Rica ${ }^{94}$, ANPA) poseen esta orientación bienestarista. Esto explica por qué dichas organizaciones ya no suelen participar en acciones colectivas y ahora se centran en campañas de castración y campañas educativas, además de brindar asesoría legislativa en el caso de $\mathrm{ABAA}^{95}$.

No obstante, sí es posible observar la lógica del medio como mensaje en círculos específicos al interior del Movimiento, en concreto, las pocas ONGs activas que se identifican como abolicionistas. De ellas es el FRAT la más influyente, que ha generado acciones encaminadas a cambiar el estilo de vida de sus activistas como forma de transformar la realidad social. Animal Save Costa Rica es una ONG incipiente que parece dirigirse por un camino similar en la corriente de la Liberación Animal, con la diferencia de que la organización se identifica con la no-violencia ${ }^{96}$.

Prueba de la utilización del medio como mensaje se puede encontrar en las palabras de Boris \& Edgar (comunicación personal, 23 de agosto de 2018): “Antes el colectivo era más de manifestaciones [...] todavía se participa, pero no tanto como al principio. Ahora es un trabajo más interno, más de autoeducación de diferentes temas, como feminismo, antiespecismo, anarquismo". Además agregan que "Ahora se convence a la gente pero de otra forma: con el Mercadito Vegano, que es como una red de cooperativismo con otras organizaciones" $"$.

Quizás porque la organización como objetivo en sí misma no es una característica distintiva del Movimiento Animalista en Costa Rica, las debilidades que, según Melucci, trae este elemento tampoco se encuentran marcadamente presentes. Es cierto que ha habido tensiones entre los liderazgos y divisiones que

\footnotetext{
89 PINTOR MORENO, Y. Comunicación personal (14 de julio de 2020).

${ }^{90}$ SEQUEIRA, A. Aprobada ley de bienestar animal: penas por maltrato serán hasta de 3 años de cárcel, en La Nación (26 de julio de 2016). Página Web: https://www.nacion.com/el-pais/aprobada-ley-de-bienestar-animal-penas-por-maltrato-seran-hasta-de-3-anos-decarcel/CHBOFUJ2FNBJPN3BHYNERYEYXQ/story/

${ }^{91}$ PINTOR MORENO, Y. Comunicación personal (14 de julio de 2020).

${ }^{92}$ PINTOR MORENO, Y. Comunicación personal (14 de julio de 2020).

${ }^{93}$ MELUCCI, A. Acción colectiva, vida cotidiana y democracia (Ciudad de México 1999) 74 y 75.

${ }^{94}$ Yadira Pintor no considera que su grupo se trate de una organización como tal, y en su lugar plantea que buscaba generar un movimiento para unir a los otros movimientos. No obstante, para efectos de esta investigación se considera que contar con una agenda definida, con una estrategia de mercadotecnia para llegar a un público determinado y con voluntarios para las actividades, son características organizativas mínimas que lo hacen calificar como una ONG cuyo fin era la aprobación de la Ley y que eventualmente fue siendo asimilada dentro de ABAA. PINTOR MORENO, Y. Comunicación personal (14 de julio de 2020).

${ }^{95}$ VICO PESCH, G. Comunicación personal (21 de agosto de 2018); PERALTA, J. Comunicación personal (15 de noviembre de 2017).

${ }^{96}$ Animal Save Costa Rica. Página Web:

https://www.facebook.com/animalsavecostarica/photos/a.1784633811834275/2339417203022597

${ }^{97}$ BORIS \& EDGAR. Comunicación personal (23 de agosto de 2018).
} 
dieron origen a ONGs nuevas (ABAA a partir de ANPA), y Pintor Moreno ${ }^{98}$ incluso sostiene que se trata de un grupo complicado con intereses separados, pero a pesar de estas situaciones, lo cierto es que dichas organizaciones han logrado sobrevivir al paso del tiempo a pesar de sus matices y no pareciera haber indicios de que el Movimiento se encuentra en riesgo inminente de fragmentación, aunque sí de desaparecer al menos por un tiempo.

Por otra parte, sí es posible identificar una variedad ideológica interna, y aunque predominan los grupos bienestaristas con un enfoque marcadamente institucional, su relativa armonía con los abolicionistas ha permitido que los segundos también puedan generar sus acciones sin obstáculos significativos. Incluso, puede afirmarse que la existencia de los grupos abolicionistas provee la única fuente de acciones colectivas en la presente fase del Movimiento marcada por la pasividad. Pero, si bien ambas visiones han logrado coexistir, no han estado exentas de tensiones.

En una de las marchas para la ley contra el maltrato animal, creo que la segunda, fue nuestra primera aparición. Éramos como unos ocho, y más que todo anarco-punks. Y siento que sorprendió a otros colectivos en esa marcha porque algunos andábamos con la cara tapada, con pasamontañas. Y cuando llegamos a la [Plaza de la] Democracia comenzamos a gritar "Carnívoros asesinos" y cosas por el estilo, y eso como que sorprendió a algunas personas" $"$.

De esta manera se aprecia como los grupos abolicionistas generaron sus roces con el sector predominante, de orientación bienestarista, del Movimiento. En seguida se presenta la misma situación percibida desde el enfoque opuesto: "Si bien es cierto, llegaban muchos veganos, vegetarianos, gente ya extremista, llegaban a veces ya a protestar por todo, llegaban ahí con máscaras de animales, con pancartas de animales muertos..."100.

En cuanto a la dificultad de conciliar demandas con los partidos políticos, este tampoco pareciera ser un problema significativo, y más bien, como se explicó recientemente, fue la apertura institucional y la alianza política del momento lo que facilitó que el Movimiento encontrara la oportunidad idónea para que se aprobara la Ley que finalmente lo aglutinó. Inclusive es posible encontrar el caso del FA, que formalizó el Frente de Protección Animal, órgano interno dedicado a canalizar las demandas animalistas ${ }^{101}$.

Para ir cerrando con la caracterización general del Movimiento Animalista, es oportuno mencionar los repertorios de acción implementados. Así, es evidente que la marcha aparece como instrumento central para movilizar a la Sociedad Civil, pero otros repertorios que fueron frecuentemente utilizados se tratan de las concentraciones en lugares donde se generan situaciones de explotación como redondeles y zoológicos, el teatro guerrilla, los "moral shocks"102 y la difusión de mensajes a través de afiches, "brochures", pancartas y medios de comunicación masivos ${ }^{103}$. Una vez identificados los repertorios de acción, es tiempo de pasar a analizar las estrategias específicas en las cuales se enmarcan.

Así, la difuminación de fronteras gracias al empleo de estrategias universalistas se puede encontrar en sus dos formas principales: la universalización de las víctimas humanas y no humanas, y la universalización de las luchas de distintos movimientos sociales ${ }^{104}$. En el primer caso se identificó el argumento, impartido durante las marchas contra el maltrato animal, de la importancia de erradicar la violencia contra los animales porque esta corresponde con la antesala a otras formas de violencia ejercidas sobre las personas:

en algún momento dábamos segmentos informativos, dábamos charlas, yo hablaba sobre el tema de indicadores, de qué pasaba si un niño maltrataba a un animal, lo que podría estar viviendo el niño, qué había pasado con el tema de agresores, cuáles eran los patrones de los psicópatas, dando esa información que la gente no conocía para crear consciencia ${ }^{105}$.

\footnotetext{
98 PINTOR MORENO, Y. Comunicación personal (14 de julio de 2020).

${ }^{99}$ BORIS \& EDGAR. Comunicación personal (23 de agosto de 2018).

${ }^{100}$ PINTOR MORENO, Y. Comunicación personal (14 de julio de 2020).

${ }^{101}$ Partido Frente Amplio. Estatuto (San José 2019) 34.

102 El "moral shock" es descrito como una táctica de reclutamiento en que un evento o situación provocan una sensación de indignación tal que inclina a las personas hacia la acción política, aun en la ausencia de una red de contactos. Los "moral shocks" les demuestran a las personas que el mundo no es como habían pensado. Ver JASPER, J. Emotions and Social Movements: Twenty Years of Theory and Research, en Annual Review of Sociology 37 (2011) 292; JASPER, J., POULSEN, J. Recruiting strangers and friends: Moral shocks and social networks in animal rights and antinuclear protest, en Social Problems 42 (1995) 198.

${ }^{103}$ PINTOR MORENO, Y. Comunicación personal (14 de julio de 2020); DURÁN, H. Comunicación personal (31 de enero de 2020); BORIS \& EDGAR. Comunicación personal (23 de agosto de 2018).

${ }^{104}$ CHERRY, E. Shifting Symbolic Boundaries: Cultural Strategies of the Animal Rights Movement, en Sociological Forum 25 (2010) 461 y 466.

105 PINTOR MORENO, Y. Comunicación personal (14 de julio de 2020).

76 Derecho Animal. Forum of Animal Law Studies, vol. 12/1
} 
La segunda estrategia universalista se encuentra especialmente presente entre los sectores abolicionistas, por ejemplo, en el FRAT:

conforme avanzaban los años, el colectivo entendió que solo la lucha contra la liberación animal no era suficiente, que igual todas las luchas están entrelazadas y que la liberación humana conlleva la liberación animal y la liberación de la tierra, y ya empezamos a acuerpar otras manifestaciones y movimientos sociales como la marcha del primero de mayo o el movimiento contra los desalojos a campesinos en la Zona Sur ${ }^{106}$.

En la misma línea, Animal Save Costa Rica ha manifestado lo siguiente:

Animal Save Costa Rica se desarrolla desde la interseccionalidad, esto con el fin de crear espacios seguros, libres de especismo, homofobia, racismo, fascismo, sexismo y machismo, donde organizadores / as como voluntarios / as se relacionan desde el respeto, la apertura, la sana convivencia y la no violencia ${ }^{107}$.

De esta forma, queda en claro la importancia que han dado estas agrupaciones a que las luchas animalistas no permanezcan aisladas, sino que se logren vincular con otras luchas contra hegemónicas.

Pasando ahora a la combinación de fronteras, se ha de decir que no se han identificado casos de desmantelamiento de la frontera entre animales de compañía y animales de producción. No obstante, sí se aprecian ejemplos de desmantelamiento de la frontera animal-humano en los "performances" de teatro guerrilla que realiza el FRAT, por ejemplo, en el marco de la concentración contra Procter \& Gamble, tanto en la demostración del trato que reciben los animales en un matadero como la demostración de la crueldad de la industria cosmética y la experimentación animal.

Cabe agregar que, a pesar de que no se han identificado este tipo de representaciones iconográficas por parte de los grupos bienestaristas, parece ser que sus detractores sí los relacionan despectivamente con el desmantelamiento de la frontera animal-humano, ya que son recurrentes los reclamos de personas que los acusan de defender a los animales en lugar de luchar por otras poblaciones vulnerables, en especial, se les acusa de preferir ayudar a los animales que a los niños ${ }^{108}$.

Estas críticas recurrentes a los activistas animalistas ofrecen indicios de que sí se podría estar dando un choque entre los ideales que buscan integrar en la sociedad y las normas ya establecidas ${ }^{109}$. Pero ¿es cierto, como sostienen los autores, que los "performances" les ayudan a conciliar esta disyuntiva?

Parece ser que en el caso de los sectores abolicionistas no se cumple esta afirmación, específicamente, el FRAT no pareciera emplear "performances" para evitar que sus ideales se muestren transgresores de la sociedad, y más bien todo su discurso y formas de acción buscan demostrar rebeldía frente al orden hegemónico. En el caso de este grupo, el "performance" más bien cumple la función de "moral shock", lo cual emplean como táctica para convencer a la gente sin tener que renunciar a la transgresión, es decir, buscan que el impacto emocional al tomar consciencia de los actos de explotación hacia los animales sea suficientemente fuerte como para generar simpatía con su orientación anti sistémica.

En cambio, aunque los bienestaristas no realizan los "performances" explícitos del teatro guerrilla, sí es posible encontrar acciones que llevan implícito el carácter ritual que tiene por objetivo demostrar que el Movimiento Animalista no está conformado por rebeldes, sino por personas humanas que buscan legitimar el repudio al maltrato animal al darle un rango legal a normas que ya se encontrarían naturalizadas dentro de la sociedad, con lo cual podrán ser penalizadas las personas que se salen de esta normalidad.

Pintor Moreno ${ }^{110}$ expresó que "la idea fue ya empezar a buscar artistas. ¿Para qué? Para que la feria de bienestar animal no se volviera como algo de solo protesta, sino que fuera un tema bonito", demostrando así la intención de buscar que los activistas sean considerados personas que actúan dentro de los límites institucionales y alejarse de la etiqueta de transgresores.

Ahora bien, como Alexander ${ }^{111}$ afirma que los actores deben conseguir objetos que sirvan de representaciones icónicas para generar identificación a través de la dramatización, es importante buscar cuáles

\footnotetext{
${ }^{106}$ BORIS \& EDGAR. Comunicación personal (23 de agosto de 2018).

${ }^{107}$ Animal Save Costa Rica. Página Web:

https://www.facebook.com/animalsavecostarica/photos/a.1784633811834275/2339417203022597

${ }_{108}$ PINTOR MORENO, Y. Comunicación personal (14 de julio de 2020); Durán, H. Comunicación personal (31 de enero de 2020).

109 JACOBSSON, K., LINDBLOM J. Moral Reflexivity and Dramaturgical Action in Social Movement Activism: The Case of the

Plowshares and Animal Rights Sweden, en Social Movement Studies 11 (2011) 41 y 45.

${ }^{110}$ PINTOR MORENO, Y. Comunicación personal (14 de julio de 2020).

111 ALEXANDER, J. Cultural Pragmatics: Social Performance between Ritual and Strategy, en Sociological Theory 22 (2004) 532 y 548.
} 
son estos objetos en el caso de interés. Los bienestaristas emplearon la difuminación de fronteras para identificar la violencia hacia las personas con la violencia hacia los animales, pero fueron más allá, pues si bien no difuminaron la frontera entre mascotas y animales de producción, sí emplearon mascotas para generar identificación con otras mascotas:

Invitábamos a los que eran como los mártires del maltrato animal, animales... no sé si vos te acordás de un perrito que le cortaron de un machetazo el hocico, no tenía hociquito [...] Y la gente al ver esos casos, es donde realmente se sensibilizaba más ${ }^{112}$.

Es decir, para intentar ayudar a erradicar el maltrato a las mascotas deciden dar carácter de objeto a algunas de ellas con la intención de que esto genere identificación y empatía entre dichos perros y las mascotas de los espectadores. En otras palabras, los perros martirizados se convierten en los objetos del ritual.

Claro está, también las personas mismas se convierten en los objetos icónicos de los rituales cuando los activistas desdibujan las fronteras entre la violencia que sufren los animales y la violencia hacia personas vulnerables, o en caso contrario, las muertes simbólicas de los adversarios se convirtieron en el objeto del ritual cuando un grupo de manifestantes quemó los muñecos de diputados opositores al proyecto de ley. Pero los abolicionistas llevan esto más allá cuando emplean sus propios cuerpos para representar el sufrimiento que sufren los animales de experimentación. Este es el ejemplo más claro del cuerpo del actor como objeto del ritual.

La performatividad no es algo exclusivo de los activistas recientes, sino que antes de la conformación del Movimiento ya se apreciaban actos performativos entre los animalistas de ANPA en el siglo pasado. Un caso de especial interés sucedía en las protestas en redondeles durante los $70 \mathrm{~s}$ y $80 \mathrm{~s}$ :

"y tuvimos que meternos en un mundo de un machismo recalcitrante, entonces había que llegar [...] a la plaza de toros con mucho mucho respeto, no llegar a imponerse porque aquí vengo yo a decirle a usted qué es lo que debe hacer / no debe hacer legalmente, a dialogar, vestidas de mujer y comportándose como mujer. Entonces yo le decía a las compañeras- La que va a ir de pantalones está bien, pero póngase una blusa bien femenina, todo el mundo con adornos en el cabello, maquilladas, con aretes, con flores" $" 113$.

En este caso se evidencia que, en el contexto de la época, las activistas tuvieron que recurrir a afianzar los roles de género como objeto ritual, no ya solo con miras a convencer a los participantes y espectadores, sino también para que la acción colectiva fuera tolerada y que así disminuyera el riesgo que corrían sus vidas en aquel entorno. Otro caso de interés que explica Hilda Durán, esta vez en el marco de la lucha contra los galleros, es el siguiente:

Íbamos con la policía, los galleros a veces muy hábilmente cambiaban y mandábamos espías entre comillas. Pero teníamos que cerciorarnos que el espía iba a tener un entrenamiento entre comillas. Cómo se iba a parar a la orilla del redondel donde estaban peleando los gallos, porque depende de la forma en que ese hombre se parara iba a ser visto como una autoridad, porque la autoridad en esa época tenía cierta forma de pararse, los varones. Inmediatamente iba a ser detectado. [...] Que a veces iba y ya había una fuga de información y ya está, ya no pelearon gallos en esa época ${ }^{114}$.

Este ejemplo demuestra que ya la performatividad jugaba un rol importante que generaba interacciones complejas entre los actores involucrados: por un lado, había posturas corporales que identificaban claramente a los hombres que eran percibidos como autoridades, lo cual corresponde con un primer aspecto del "performance" situado a nivel macrosocial. El otro aspecto es que tanto los galleros como los activistas eran conscientes de esta situación, lo cual incitaba a los primeros a idear tácticas de identificación de infiltrados y posibles protocolos para evadir a las autoridades, y llevaba a los activistas a tener que idear "performances" con la suficiente sofisticación como para poder pasar desapercibidos ante sus adversarios.

\section{Conclusiones}

Una vez finalizado el análisis, fueron identificadas las principales oportunidades que le permitieron a los liderazgos bienestaristas del Movimiento Animalista llevar la lucha por la ley contra el maltrato animal

112 PINTOR MORENO, Y. Comunicación personal (14 de julio de 2020).

${ }^{113}$ DURÁN, H. Comunicación personal (31 de enero de 2020).

114 DURÁN, H. Comunicación personal (31 de enero de 2020).

78 Derecho Animal. Forum of Animal Law Studies, vol. 12/1 
hasta su aprobación efectiva. De igual manera se identificaron sus motivaciones y las representaciones simbólicas que hicieron de estas, al tiempo que se hizo un esbozo inicial de los mismos elementos por parte de los sectores abolicionistas. Lo anterior se debe estudiar teniendo presente que de ninguna manera se pueden generalizar los objetivos de estos actores con los de la totalidad de activistas y personas que asistieron a las marchas y demás acciones colectivas.

El hallazgo más evidente es que la constitución del Movimiento giró en torno a lucha por la obtención de una ley que permitiera penalizar el maltrato hacia los animales, enfocada en las mascotas. Esto refleja una predilección por la canalización de demandas a través de la vía institucional aun si se emplearon acciones colectivas como instrumentos de presión, lo cual entra en sintonía con los hallazgos de otros investigadores que han identificado una tendencia histórica por parte de la Sociedad Civil costarricense de canalizar los conflictos por medio de las instituciones ${ }^{115}$.

Es importante destacar que, si bien el Movimiento Animalista se articula en 2009, las primeras acciones colectivas e institucionales en favor de los animales se pueden rastrear desde inicios del siglo XX. Aunque la mayor parte de los grupos destacados dentro del Movimiento poseen una orientación bienestarista, en años recientes se ha hecho manifiesta la aparición de demandas más claramente antiespecistas por parte de las organizaciones abolicionistas.

Estos son los grupos que pueden reactivar el Movimiento luego de la aprobación de la ley, y sus principales retos serán: en primer lugar, superar las etiquetas peyorativas que podrían haber obtenido debido a su perfil transigente, y de segundo, lograr que las demandas antiespecistas adquieran un carácter de centralidad dentro del Movimiento Animalista con un impulso capaz de movilizar a la Sociedad Civil. Por su parte, las organizaciones bienestaristas han de acompañar a los sectores mencionados intentando ofrecer su guía sin actitudes paternalistas, a la vez que deberán presionar al Estado para hacer cumplir la Ley $\mathrm{N}^{\circ} 9458$ en medio de un ambiente político marcado por la austeridad fiscal.

\section{Referencias bibliográficas}

- ALBA, R. Bright vs. blurred boundaries: Second-generation assimilation and exclusion in France, Germany, and the United States, en Ethnic and Racial Studies 28 (2010) 20-49.

- ALEXANDER, J. Cultural Pragmatics: Social Performance between Ritual and Strategy, en Sociological Theory 22 (2004) 527-573.

- ALPÍZAR, F. ¿Democracia ecológica? Las instituciones, la participación política y las contiendas por el agua en Costa Rica (1821-2010) (Tesis para optar por el grado de Doctor en Ciencias Políticas) (Madrid 2013).

- Animal Save Costa Rica. Página https://www.facebook.com/animalsavecostarica/photos/a.1784633811834275/2339417203022597

- Animal Save Costa Rica. Página Web: https://www.instagram.com/p/CE5WjViJGFv/?igshid=iw9bs4o5kz6t

- Animal Save Costa Rica. Página Web: https://www.instagram.com/p/CEEkUCRJd13/?igshid=hnbe7f703zcj

- Animal Save Costa Rica. Pégina https://www.facebook.com/events/306040743774113/?acontext=\%7B\%22source $\% 22 \% 3 \mathrm{~A} 5 \% 2 \mathrm{C}$ $\% 22$ action history $\% 22 \% 3 \mathrm{~A}[\% 7 \mathrm{~B} \% 22$ surface $\% 22 \% 3 \mathrm{~A} \% 22$ page $\% 22 \% 2 \mathrm{C} \% 22$ mechanism $\% 22 \% 3$ A $\% 22$ main_list $\% 22 \% 2 \mathrm{C} \% 22$ extra_data\%22\%3A\%22\%5C\%22[]\%5C $\% 22 \% 22 \% 7 \mathrm{D}] \% 2 \mathrm{C} \% 22 \mathrm{has}$ _source $\% 22 \% 3$ Atrue $\% 7 \mathrm{D}$

- Asamblea Legislativa de la República de Costa Rica. N9106 REFORMAS Y ADICIONES A LA LEY DE CONSERVACIÓN DE VIDA SILVESTRE, LEY N. ${ }^{\circ}$ 7317, DE 30 DE OCTUBRE DE 1992, en La Gaceta 75 (24 de abril de 2013).

- Asamblea Legislativa de la República de Costa Rica. N9458 REFORMAS DE LA LEY N. ${ }^{\circ} 4573$, CÓDIGO PENAL, DE 4 DE MAYO DE 1970 Y REFORMAS DE LA LEY N. ${ }^{\circ} 7451$, BIENESTAR DE LOS ANIMALES, DE 16 DE NOVIEMBRE DE 1994, en La Gaceta 152 (26 de junio de 2017).

- Asociación Nacional Protectora de Animales. Página Web: https://www.facebook.com/pg/ANPACR/about/?ref=page_internal

- BARAHONA RIERA, M. Las sufragistas de Costa Rica (San José 1994).

- CABIBBO GUILLÉN, M. Garantías jurídicas para la protección de los animales domésticos (Tesis

115 ALPÍZAR, F. ¿Democracia ecológica? Las instituciones, la participación política y las contiendas por el agua en Costa Rica (18212010) (Tesis para optar por el grado de Doctor en Ciencias Políticas) (Madrid 2013) 93; MOLINA, I. Catolicismo y comunismo en Costa Rica (1931-1940), en Desacatos 22 (2006) 158. 
para optar por el grado de Master Profesional en Derecho Ambiental) (San José 2014).

- CALVO, N. Presidente firma Ley de Bienestar Animal, en La Nación (11 de junio de 2017). Página Web: $\quad$ http://www.nacion.com/ciencia/medio-ambiente/presidente-firma-ley-de-bienestaranimal/ASRB62SOUZEBTHKX7NUE5TGHQQ/story/

- CAMACHO CHACÓN, J. CASTRO MURILlO, M., REYES MORENO, L. La ciencia del bienestar animal: conceptualización y discusión, en Rev. Filosofía Univ. Costa Rica 58 (2019) 8998.

- CERDAS, D. Ley contra maltrato animal se convirtió en un fiasco, en La Nación (26 de enero de 2020). Página Web: https://www.nacion.com/el-pais/gobierno/ley-contra-maltrato-animal-seconvirtio-en-un/RMNWMNH7ZFD7VGQKIMD7J3SIGU/story/

- CHERRY, E. Shifting Symbolic Boundaries: Cultural Strategies of the Animal Rights Movement, en Sociological Forum 25 (2010) 450-475. DOI: 10.1111/j.1573-7861.2010.01191.x

- FERNÁNDEZ RIVERA, F. Juegos de gallos. Un veto histórico y un discurso parlamentario olvidado (San José 1984).

- Frente de Resistencia Animal y de la Tierra. Página Web: https://frat.noblogs.org/post/2013/08/02/comunicado-en-referencia-a-la-marcha-por-la-liberacionanimal/

- Frente de Resistencia Animal y de la Tierra. Página Web: https://frat.noblogs.org/post/2014/05/17/concentracion-informativa-anti-proctergamble-2014/

- Frente de Resistencia Animal y de la Tierra. Página Web: https://frat.noblogs.org/post/2011/12/26/manifiesto-anti-corridas-de-zapote 2011-antitaurino/

- Frente de Resistencia Animal y de la Tierra. Página Web: https://frat.noblogs.org/post/2013/08/02/posicion-ante-los-zoologicos/

- Frente de Resistencia Animal y de la Tierra. Página Web: https://www.instagram.com/p/B7rqiVTlttU/?igshid=tztrkdlupvr; Boris \& Edgar. Comunicación personal (23 de agosto de 2018).

- Frente de Resistencia Animal y de la Tierra. Página Web: https://www.instagram.com/p/CJT3QupBBdP/?igshid=5ha1g95n0ql3

- Frente de Resistencia Animal y de la Tierra. Página Web: https://www.instagram.com/p/CH8RV0ZnXyx/?igshid=vcgptn9i0yj1

- Frente de Resistencia Animal y de la Tierra. Página Web: https://www.instagram.com/p/CIIinEVH4o1/?igshid=1qobihy0f7xi3

- Furia Antiespecista. Página Web: https://www.instagram.com/p/B6tq16yHTAi/?igshid=5iisyogahi0w

- Furia Antiespecista. Página Web: https://www.instagram.com/p/B9AAQ2on3zm/?igshid=1 crhi9bka2gh0

- GEORGE, A., BENETT, A. Case studies and Theory Development in the Social Sciences (Massachusetts 2005).

- GOFFMAN, E. The Representation of Self in Everyday Life (Edinburgh 1956).

- GRANADOS-ZÚÑIGA, J. Uso de animales de experimentación en la investigación biomédica en Costa Rica, en Acta méd. costarric. 52 (2010) 134-136.

- GRANADOS-ZÚÑIGA, J., PAZOS SANOU, L. Legislación para el uso de animales de laboratorio en Costa Rica, en Med. leg. Costa Rica 15 (1998) 1-6.

- HALL, R. Communitarian Ethics and the Sociology of Morals: Alasdair Maclntyre and Emile Durkheim, en Sociological Focus 24 (1991) 93-104.

- JACOBSSON, K., LINDBLOM J. Moral Reflexivity and Dramaturgical Action in Social Movement Activism: The Case of the Plowshares and Animal Rights Sweden, en Social Movement Studies 11 (2011) 41-60.

- JASPER, J. Emotions and Social Movements: Twenty Years of Theory and Research, en Annual Review of Sociology 37 (2011) 285-303. DOI: 10.1146/annurev-soc-081309-150015

- JASPER, J., POULSEN, J. Recruiting strangers and friends: Moral shocks and social networks in animal rights and antinuclear protest, en Social Problems 42 (1995) 493-512. DOI: 0.1525/sp.1995.42.4.03x0129y

- LAMONT, M., BAIL, C. Bridging Boundaries: The Equalization Strategies of Stigmatized Ethnoracial Groups Compared, en Center for European Studies Working Paper Series (2008) 1-28.

- MADRIGAL RODRÍGUEZ, L. Legislación de bienestar animal en Costa Rica: Un análisis jurídicoformal sobre la protección legal animal y el proceso del proyecto de ley penalización del maltrato 
animal (Tesis para optar por el grado de Licenciatura en Derecho) (San José 2015).

- MATA BLANCO, E. Zafarrancho entre "ambientalistas" por quema de imágenes de Ottón Solís y Otto Guevara, en La Nación (14 de abril de 2016). Página Web: https://www.nacion.com/elpais/politica/zafarrancho-entre-ambientalistas-por-quema-de-imagenes-de-otton-solis-y-ottoguevara/HXYBBDCFC5C3HBVX5UUVM6ZIAU/story/

- MELUCCI, A. Acción colectiva, vida cotidiana y democracia (Ciudad de México 1999).

- MOLINA, I. Catolicismo y comunismo en Costa Rica (1931-1940), en Desacatos 22 (2006) 157172.

- MORALES PICADO, A. Derecho de los animales en el sistema jurídico costarricense: un análisis desde una perspectiva axiológico-jurídica (Tesis para optar por el grado de Licenciatura en Derecho) (San José 2015).

- PARRA, J. El arte del muestreo cualitativo y su importancia para la evaluación y la investigación de políticas públicas: una aproximación realista, en OPERA 25 (2019) 119-136.

- Partido Acción Ciudadana. Página Web: https://pac.cr/pac-mantiene-su-compromiso-con-la-ley-debienestar-animal/

- Partido Frente Amplio. Página Web: https://www.frenteamplio.org/frente-amplio-protegebienestar-los-animales/

- Partido Frente Amplio. Estatuto (San José 2019).

- RODRÍGUEZ AGUILAR, O. “iSe muere gallo bueno!”. Peleas, socialidad y violencia galleras en Costa Rica, en Anuario de Estudios Centroamericanos (2015) 303-327.

- RODRÍGUEZ AGUILAR, O. Gallos de pelea: algunas precisiones desde el diálogo con un gallero, en Cuadernos de Antropología 24 (2014) 37-64.

- RODRÍGUEZ AGUILAR, O., ALPÍZAR LOBO, N. Las peleas de gallos en la prensa escrita costarricense: un Análisis Crítico del Discurso en algunas noticias del diario La Nación S.A., en Rev. Rupturas 4 (2014) 50-69.

- RODRÍGUEZ GIRALT, I. El efecto de las TIC en la organización de la acción colectiva: la virtualización de los movimientos sociales, en UOC (2002) 1-21.

- RODRÍGUEZ SEDANO, A., AGUILERA, J.C. De la constitución moral de la sociedad a la educación moral según Durkheim, en revista española de pedagogía (2009) 319-336.

- ROSALES-VALLADARES, R. Elecciones Costa Rica 2014: El aparente giro hacia el progresismo de izquierda mediante el triunfo del Partido Acción Ciudadana y el ascenso del Frente Amplio, en Anuario CIEP (2015) 155-175.

- ROSE, F. Toward a Class-Cultural Theory of Social Movements: Reinterpreting New Social Movements, en Sociological Forum 12 (1997) 461-494.

- SEQUEIRA, A. Aprobada ley de bienestar animal: penas por maltrato serán hasta de 3 años de cárcel, en La Nación (26 de julio de 2016). Página Web: https://www.nacion.com/el-pais/aprobadaley-de-bienestar-animal-penas-por-maltrato-seran-hasta-de-3-anos-decarcel/CHBOFUJ2FNBJPN3BHYNERYEYXQ/story/

- SUÁREZ ESQUIVEL, M., ESTRADA KÖNIG, S. Bienestar animal en investigación biomédica, en Rev. Ciencias Veterinarias 29 (2011) 21-35.

- TARROW, S. El poder en movimiento. Los movimientos sociales, la acción colectiva y la política (Madrid 1997).

- URBINA GAITÁN, C. Homogeneizando culturas. Peleas de gallos, corridas de toros y Estado en Costa Rica (1870-1914), en Revista de Ciencias Sociales (Cr) 3 (2000) 59-67.

- VÁZQUEZ, R., VALENCIA, A. La creciente importancia de los debates antiespecistas en la teoría política contemporánea: del bienestarismo al abolicionismo, en Revista Española de Ciencia Política (2016) 147-164. DOI: http://dx.doi.org/10.21308/recp.42.06

- WIMMER, A. Elementary strategies of ethnic boundary making, en Ethnic and Racial Studies 31 (2008) 1025-1055. DOI: 10.1080/01419870801905612

- ZELLER VAN ENGELEN, M. La protección jurídica del animal en Costa Rica (Tesis para optar por el grado de Licenciatura en Derecho) (San José 1990). 